\title{
One-Pot Hydrothermal Synthesis, Characterization, and Desulfurization Performance of $\mathrm{ZnFe}_{2} \mathrm{O}_{4} / \mathrm{AC}$ Composites
}

\author{
Hui-qiang Wang $\mathbb{D}^{1,2,3}$ Ming-hua Liu $\mathbb{D}^{1,}{ }^{1,2,3}$ Xin Luo, ${ }^{1,2,3}$ Yi-fan Liu, ${ }^{1,2,3}$ Fei-er Chen, ${ }^{1,2,3}$ \\ and Yuan-cai $\mathrm{Lv}^{1,2,3}$ \\ ${ }^{1}$ College of Environment and Resources, Fuzhou University, Fuzhou, Fujian 350108, China \\ ${ }^{2}$ Fujian Provincial Engineering Research Center for High-Value Utilization Technology of Plant Resources, Fuzhou University, \\ Fuzhou, Fujian 350108, China \\ ${ }^{3}$ Fujian Provincial Technology Exploitation Base of Biomass Resources, Fuzhou University, Fuzhou, Fujian 350108, China
}

Correspondence should be addressed to Ming-hua Liu; mhliu2000@fzu.edu.cn

Received 17 September 2017; Revised 7 December 2017; Accepted 4 January 2018; Published 20 February 2018

Academic Editor: Zupeng Chen

Copyright (c) 2018 Hui-qiang Wang et al. This is an open access article distributed under the Creative Commons Attribution License, which permits unrestricted use, distribution, and reproduction in any medium, provided the original work is properly cited.

\begin{abstract}
$\mathrm{ZnFe}_{2} \mathrm{O}_{4} / \mathrm{AC}$ composites were prepared by the one-pot hydrothermal method using the activated carbon (AC) as a carrier. The synthesis conditions were optimized by a single-factor experiment. The structural, textural, and surface properties of the adsorbent have been comprehensively characterized by scanning electron microscopy (SEM), X-ray diffraction (XRD), Fourier-transform infrared (FT-IR) spectroscopy, Brunauer-Emmett-Teller (BET) measurements, and X-ray photoelectron spectroscopy (XPS) analysis. The $\mathrm{SO}_{2}$ removal capacities of the composites were investigated via testing the adsorption capacity at the self-made desulfurization equipment. The results show that the adsorption capacity of $\mathrm{ZnFe}_{2} \mathrm{O}_{4} / \mathrm{AC}$ composites is much higher than that of the $\mathrm{AC}$ and $\mathrm{ZnFe}_{2} \mathrm{O}_{4}$ samples, respectively. The composite overcomes the disadvantages of the traditional sintering, showing a very high desulfurization performance. The breakthrough time was $147 \mathrm{~min}$, and the sulfur adsorption capacity could reach $23.67 \%$ in the desulfurization performance test.
\end{abstract}

\section{Introduction}

In recent years, with the rapid development of economy and change of the energy consumption structure, the sulfur dioxide $\left(\mathrm{SO}_{2}\right)$ emission increased gradually. $\mathrm{SO}_{2}$ is a poisonous and hazardous gas which could induce the formation of acidic rain potentially, causing a severe threat to the human health [1-3]. Therefore, a variety of methods have been developed for the removal of sulfur dioxide. Generally, the adsorption by activated carbon (AC) is a feasible strategy for desulfuration [4-6]. In this context, numerous studies have tested activated carbon, due to their unique characteristics, for example, large specific surface area, uniform pore size distribution, and amenability to surface function $[5,7,8]$. Recent studies have shown that activated carbon loaded with metal oxide or the surface functionalized with a suitable reagent is more efficient with respect to the catalytic oxidation of $\mathrm{SO}_{2}$ [9-11].
A considerable amount of research has been conducted on the suitability of various activated carbon loaded with metal oxide for $\mathrm{SO}_{2}$ removal $[1,5]$. This composite material can adsorb the contaminants more efficiently than AC or metal oxide alone. Embedding metal oxides in a precursor would enhance the gas adsorption capacity of the resulting composite AC $[12,13]$, since metal oxide could yield the selective sorbent capacity and the high thermal stability at elevated temperatures $[14,15]$. Usually, metal oxides are the potential candidates for $\mathrm{SO}_{2}$ removal. Alkali metal oxides or alkaline earth metal oxides have strong affinity to $\mathrm{SO}_{2}$ even in humid gas atmosphere [16]. Recently, Zn-Fe-based sorbents have been attracted an increasing attention for their effective adsorption of $\mathrm{SO}_{2}[17,18]$. Lee et al. [19] have demonstrated that $\mathrm{Ce}-\mathrm{Fe}-\mathrm{Mg}$-based sorbents showed excellent sulfur removal capacity and regeneration ability. Podwórny et al. [20] have interpreted the behaviors of $\mathrm{MgO}$ $\mathrm{MgFe}_{2} \mathrm{O}_{4}$ spinels in the gaseous environment having high 
concentration of $\mathrm{SO}_{2}$. However, the composite metal oxides can easily result in the formation of agglomerated particles when contacted with $\mathrm{SO}_{2}$, which strongly limits their capacity. Thus, it is of great significance to incorporate the metal oxide on the surface of activated carbon. The presence of activated carbon as a carrier can improve the dispersability of metal oxides and reduce the extent of metal oxide aggregation, ultimately strengthening the activity of desulfurization.

In this study, the composite metal oxides $\mathrm{ZnFe}_{2} \mathrm{O}_{4}$ with activated carbon materials as a substrate by one-pot hydrothermal synthesis were prepared [21]. On the basis of the conventional hydrothermal synthesis method, the compound was obtained under the dispersion effect of the surfactant cetyl trimethyl ammonium bromide, which eventually made the nanometer $\mathrm{ZnFe}_{2} \mathrm{O}_{4}$ spinel to be loaded on the activated carbon. Specifically, the developed preparation strategy of composite materials rarely requires the high-temperature calcination to yield an efficient desulfurization. This strategy also can solve the problem of the aggregation of $\mathrm{ZnFe}_{2} \mathrm{O}_{4}$, providing a potential industrial application for desulfurization.

\section{Materials and Methods}

2.1. Materials. AC supplied by Chinese Medicine Group Chemical Reagent Co., Ltd. (Shanghai, China) was grounded into particles with sizes of $0.35-0.16 \mathrm{~mm}$ (40-100 mush) as substrates. $\mathrm{Fe}\left(\mathrm{NO}_{3}\right)_{3} \cdot 9 \mathrm{H}_{2} \mathrm{O}$ and $\mathrm{Zn}\left(\mathrm{NO}_{3}\right)_{2} \cdot 6 \mathrm{H}_{2} \mathrm{O}$ of analytical grade were purchased from Tianjin Fuchen Chemical Reagent Co., Ltd., China. Cetyl trimethyl ammonium bromide (CTAB, $\mathrm{C}_{16} \mathrm{H}_{33} \mathrm{~N}^{+}\left(\mathrm{CH}_{3}\right)_{3} \mathrm{Br}^{-}$; purity: $\left.>98 \%\right)$ was obtained from Shanghai Aladdin biochemical Polytron Technologies Inc, China. $\mathrm{N}_{2}$ and $\mathrm{O}_{2}$ with purity of $99.999 \%$ were purchased from Huaxinda Gas Corporation (Fuzhou, China). $\mathrm{SO}_{2}$ was supplied by Guangdong Huate gas Limited by Share Ltd. (Guangdong, China). The simulated flue gas was prepared which contains $1000 \mathrm{ppm} \mathrm{SO}_{2}, 5 \% \mathrm{O}_{2}, 5 \%$ $\mathrm{H}_{2} \mathrm{O}$, and balance $\mathrm{N}_{2}$ gas.

\subsection{Preparation of Composite Materials}

2.2.1. Pretreatment of Activated Carbon. Firstly, activated carbon was completely washed by deionized water three times. Subsequently, it was placed at $120^{\circ} \mathrm{C}$ drying for $2 \mathrm{~h}$ and then cooled at room temperature for further use.

2.2.2. Preparation of $\mathrm{ZnFe}_{2} \mathrm{O}_{4} / A C$ Composites. $\mathrm{ZnFe}_{2} \mathrm{O}_{4} / \mathrm{AC}$ composites powder was prepared in the presence of $\mathrm{CTAB}$ by using the hydrothermal method. Briefly, 5.0 gram of AC, as the substrate, was added in the mixed solution of $100 \mathrm{~mL}$ $\mathrm{Zn}\left(\mathrm{NO}_{3}\right)_{2}(0.2 \mathrm{M})$ and $100 \mathrm{~mL} \mathrm{Fe}\left(\mathrm{NO}_{3}\right)_{3}(0.4 \mathrm{M})$, which was then mixed with $1 \mathrm{~g}$ of CTAB to form a homogeneous solution. The mixed solution, with a stoichiometric ratio of $1: 2$ ([Zn]: [Fe]), was stirred magnetically at $273 \mathrm{~K}$ for $30 \mathrm{~min}$. Sodium hydroxide solution $(6.0 \mathrm{M})$ was slowly added into the mixture to obtain a solution with a $\mathrm{pH}$ of 10.0. This solution was pretreated in an ultrasonic water bath for
$30 \mathrm{~min}$ and then transferred to a $500 \mathrm{~mL}$ Teflon-lined stainless steel autoclave to keep it at $130^{\circ} \mathrm{C}$ for $24 \mathrm{~h}$ in an oven. Subsequently, the autoclave was cooled to room temperature gradually. Finally, the precipitate was centrifuged and washed with deionized water several times to reduce the impurities in the product. The resulting product was dried in a vacuum oven at $75^{\circ} \mathrm{C}$ for $6 \mathrm{~h}$, marked as $\mathrm{ZnFe}_{2} \mathrm{O}_{4} /$ AC.

2.3. Characterization of $\mathrm{ZnFe}_{2} \mathrm{O}_{4} / \mathrm{AC}$ Composites. The obtained samples were characterized on a Rigaku D/Max2550VB/PC $\mathrm{X}$-ray powder diffractometer (XRD) with a $\mathrm{Cu} \mathrm{K} \alpha$ radiation source and operated at a voltage of $40 \mathrm{kV}$ and a current of $100 \mathrm{~mA}$. Fourier-transform infrared (FT-IR) spectra were recorded on a Nicolet FT-170SX instrument using KBr discs in the $400-4000 \mathrm{~cm}^{-1}$ region. Scanning electron microscopy (SEM) was performed with a JEOLJSM-6360 LV microscope. Chemical composition of the particles was determined by energy-dispersive spectrometry (EDS). Specific BET surface area and pore size distribution were determined with an Autosorb1-C chemisorption/physisorption analyzer (Quantachrome, USA) by nitrogen adsorption at $77.3 \mathrm{~K}$. The surface composition of the ACS-1 sorbent was obtained using a Thermo Scientific ESCALAB 250 Xi spectrometer (Thermo Fisher Scientific) equipped with monochromatic $\mathrm{Al} \mathrm{K} \alpha(1486.6 \mathrm{eV})$ $\mathrm{X}$-rays. The X-ray source was operated at $15 \mathrm{kV}$ and $10 \mathrm{~mA}$. The core-level XPS spectra for C1s, O1s, Zn2p, Fe2p, and S2p were measured at a step pace of $0.1 \mathrm{eV}$. The binding energies were calibrated taking C1s as a standard with a measured typical value of $248.6 \mathrm{eV}$. Each spectrum was fitted using a Voigt function (mixed Lorentzian-Gaussian) with Shirley backgrounds.

2.4. $\mathrm{SO}_{2}$ Adsorption Tests. The adsorption tests of $\mathrm{ZnFe}_{2} \mathrm{O}_{4} / \mathrm{AC}$ were carried out in a horizontally oriented quartz tube reactor $(16.0 \mathrm{~mm} \times 100.0 \mathrm{~mm})$, and the results were shown in Figure 1. In each experiment, ca. $1.0 \mathrm{~g}$ of the $\mathrm{ZnFe}_{2} \mathrm{O}_{4} / \mathrm{AC}$ sorbent was packed into the reactor [22]. The adsorption tests were conducted at atmospheric pressure with a temperature of $35 \pm 0.5^{\circ} \mathrm{C}$ and a gas hourly space velocity of $149.28 \pm 10 \mathrm{~h}^{-1}$. The flow rates of $\mathrm{SO}_{2}, \mathrm{O}_{2}, \mathrm{H}_{2} \mathrm{O}$, and $\mathrm{N}_{2}$ were precisely controlled by mass flow controllers. The concentration of $\mathrm{SO}_{2}$ was measured by a flue gas analyzer (model PGD3-IR, Wuhan Quartet Photoelectric Technology Co., Ltd.). When the concentration of $\mathrm{SO}_{2}$ exceeded $1000 \mathrm{ppm}$ in the outlet gas, the adsorption tests were terminated immediately. The breakthrough sulfur capacity of the $\mathrm{ZnFe}_{2} \mathrm{O}_{4} / \mathrm{AC}$ sorbent was calculated as follows [7]:

$$
S_{c}=\frac{v_{\mathrm{sp}} V_{\mathrm{bed}}}{m} \times\left[\frac{M}{V_{\mathrm{mol}}} \times \int_{0}^{t}\left(C_{\mathrm{in}}-C_{\mathrm{out}}\right) \mathrm{dt}\right],
$$

where $S_{c}$ is the breakthrough sulfur capacity of $\mathrm{ZnFe}_{2} \mathrm{O}_{4} / \mathrm{AC}$ (mg of S/g of sorbent), $v_{\mathrm{sp}}$ is the gas hourly space velocity (STP) of the simulated flue gas $\left(\mathrm{h}^{-1}\right), V_{\text {bed }}$ is the volume of the sorbent in the reactor $(\mathrm{mL}), m$ is the weight of the sorbent in the reactor $(\mathrm{g}), M$ is the atomic weight of sulfur 


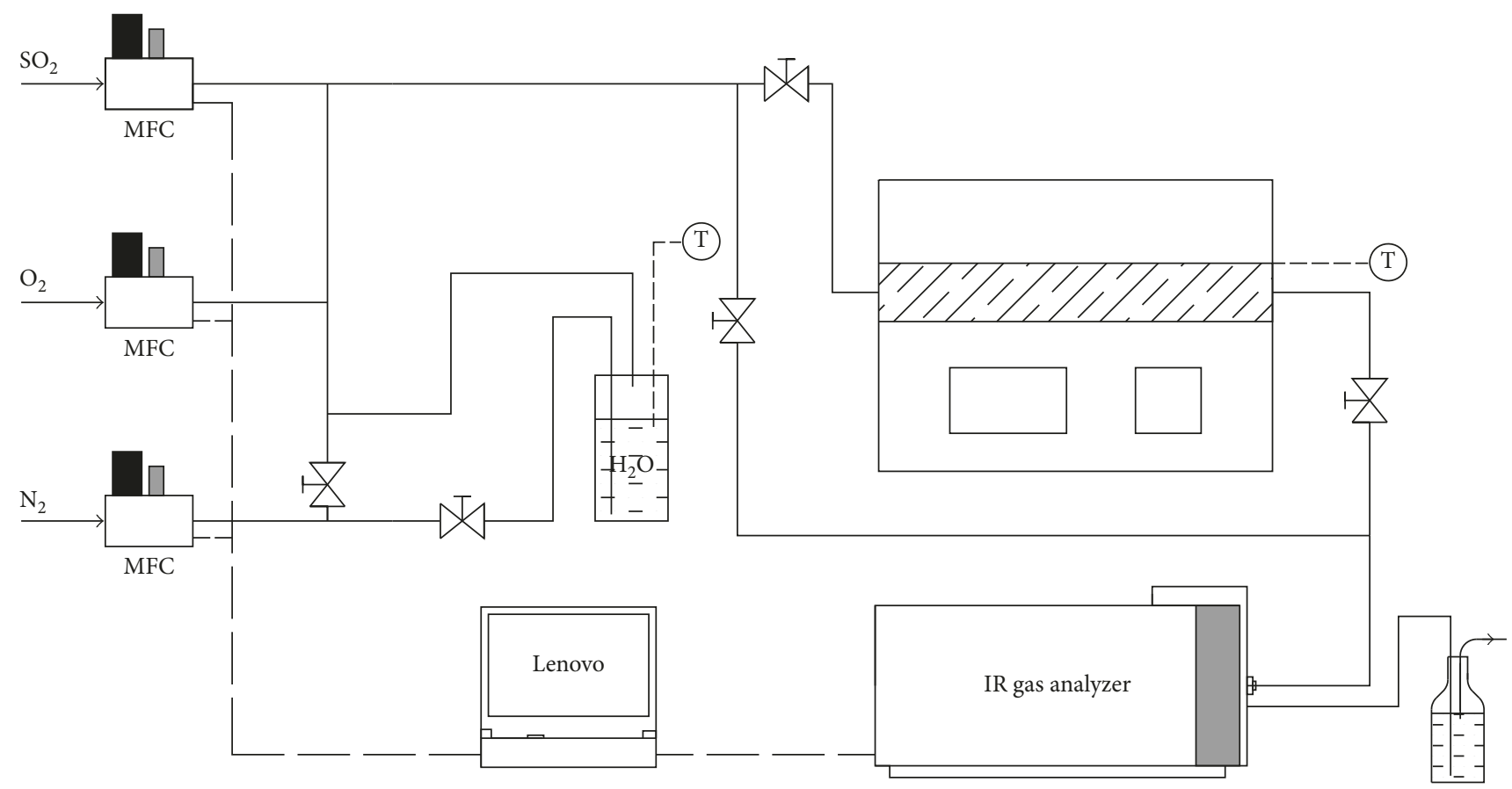

FIgURE 1: Schematic for device processing. MFC: mass flow controller; T: temperature controller.

$\left(\mathrm{g} \cdot \mathrm{mol}^{-1}\right), V_{\mathrm{mol}}$ is the molar volume of gas $\left(22.4 \mathrm{~L} \cdot \mathrm{mol}^{-1}\right.$ under standard conditions), $C_{\text {in }}$ and $C_{\text {out }}$ are the inlet and outlet total $\mathrm{SO}_{2}$ concentrations (\%), and $t$ is the breakthrough time (BT) (h).

2.5. The Load Rate of $\mathrm{ZnFe}_{2} \mathrm{O}_{4}$ on $\mathrm{ZnFe}_{2} \mathrm{O}_{4} / A C$ Composite. The $\mathrm{ZnFe}_{2} \mathrm{O}_{4} / \mathrm{AC}$ composite was calcined at $1000^{\circ} \mathrm{C}$ for $2 \mathrm{~h}$. The activated carbon was completely burned, and the rest was $\mathrm{ZnFe}_{2} \mathrm{O}_{4}$. The $\mathrm{ZnFe}_{2} \mathrm{O}_{4}$ load rate is the remaining $\mathrm{ZnFe}_{2} \mathrm{O}_{4}$ mass divided by the quality of the burned activated carbon (AC).

$$
R=\frac{m_{s}}{m_{b}}
$$

where $R$ is the $\mathrm{ZnFe}_{2} \mathrm{O}_{4}$ load rate on activated carbon per unit mass ( $\mathrm{g}$ of $\mathrm{ZnFe}_{2} \mathrm{O}_{4} / \mathrm{g}$ of $\mathrm{AC}$ ), $m_{s}$ is the remaining $\mathrm{ZnFe}_{2} \mathrm{O}_{4}$ mass $(\mathrm{g})$, and $m_{b}$ is the quality of the burned activated carbon $(\mathrm{g})$.

\section{Results and Discussion}

3.1. Preparation of $\mathrm{ZnFe}_{2} \mathrm{O}_{4} / A C$ Composite. In the process of preparing the $\mathrm{ZnFe}_{2} \mathrm{O}_{4} / \mathrm{AC}$ composite material by hydrothermal synthesis, the load ratio, ultrasonic time, and drying temperature have severe influence on the adsorption performance for $\mathrm{SO}_{2}$ removal.

\subsubsection{Effect of Mass Ratio between Zinc Ferrite and Activated} Carbon on Desulfurization. As shown in Figure 2, the mass ratio of zinc ferrite to activated carbon is an important factor affecting the adsorption performance of $\mathrm{ZnFe}_{2} \mathrm{O}_{4} / \mathrm{AC}$ composites on $\mathrm{SO}_{2}$ removal. In order to study the effect of the adsorption performance on $\mathrm{SO}_{2}$ removal through the

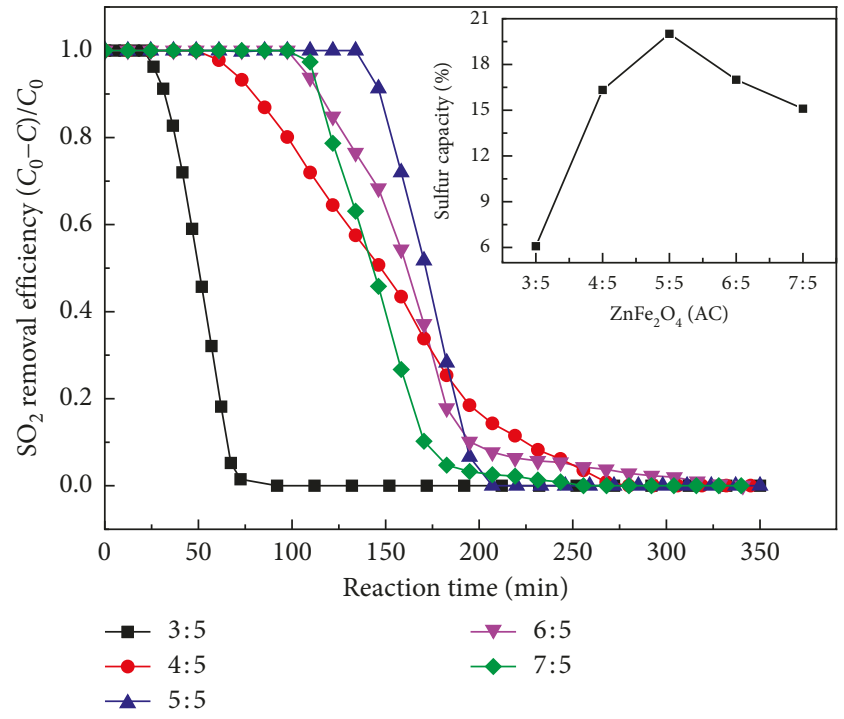

FIGURE 2: Effect of zinc ferrite/activated carbon at different mass ratios on desufurization reactivity.

change of mass ratio $(3: 5,4: 5,5: 5,6: 5$, and $7: 5)$, the ultrasonic time was set for $60 \mathrm{~min}$ and the reaction temperature set at $130^{\circ} \mathrm{C}$. The result showed that the sulfur adsorption capacity gradually increased when the mass ratio of zinc ferrite to activated carbon increased from $3: 5$ to $5: 5$. However, the mass ratio reached $6: 5$, and the sulfur capacity of composites gradually declined. Therefore, when the mass ratio was set to $5: 5$, the composite material has the best adsorption performance for $\mathrm{SO}_{2}$ removal with largest sulfur capacity. The main reason was due to the fact that a small amount of zinc ferrite loading causes a low adsorption 


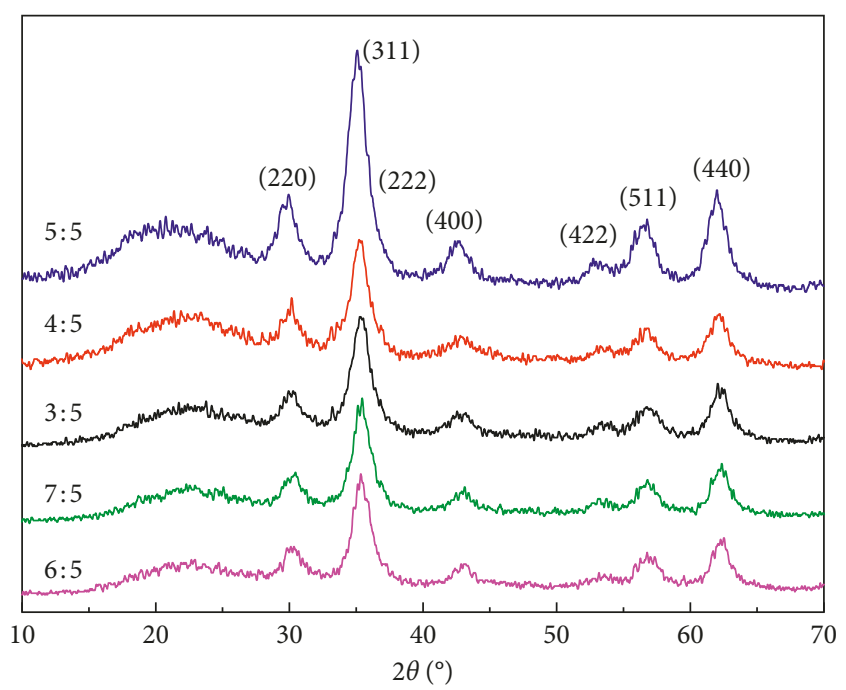

FIGURE 3: XRD pattern of zinc ferrite/activated carbon at different mass ratios.

activity and sulfur capacity. However, at high $\mathrm{ZnFe}_{2} \mathrm{O}_{4}$ load, the multilayer coverage phenomenon at the pore structure of activated carbon occurs, resulting in the decreased effective surface area and decreased capacity of the sulfur desulfurization agent.

The $\mathrm{ZnFe}_{2} \mathrm{O}_{4} / \mathrm{AC}$ composite powder, prepared at different mass ratios of zinc ferrite to activated carbon, was also characterized by XRD (Figure 3). XRD patterns showed that $\mathrm{ZnFe}_{2} \mathrm{O}_{4} / \mathrm{AC}$ composite powder had cubic spinel structures, which were consistent with the values reported in the database of $\mathrm{ZnFe}_{2} \mathrm{O}_{4}$ (JCPDS 22-1012). The peak intensity reached the highest position at the mass ratio of $5: 5$.

\subsubsection{Effect of Ultrasonic Time on Desulfurization Ability of} $\mathrm{ZnFe}_{2} \mathrm{O}_{4} / A C$ Composite. In this case, the experiment controls the condition of the mass ratio of zinc ferrite to activated carbon being at 5:5, and the hydrothermal temperature was set at $130^{\circ} \mathrm{C}$. The impact of ultrasonic time on desulfurization ability of the $\mathrm{ZnFe}_{2} \mathrm{O}_{4} / \mathrm{AC}$ composite was discussed (Figure 4). Table 1 shows the influence of ultrasonic time on the $\mathrm{ZnFe}_{2} \mathrm{O}_{4}$ load ratio.

As shown in Figure 4, without ultrasonic waves, the sulfur capacity reached only $8.85 \%$, while the sulfur capacity of the desulfurizer was enhanced as the ultrasonic duration prolonged. The adsorption capacity of the desulfurizer was enhanced significantly with the effect of ultrasonic waves. When the ultrasonic time was at $60 \mathrm{~min}$, the optimal sulfur capacity of the desulfurizer reached $20.01 \%$. It can be seen that, during the preparation of the desulfurizer, the force generated and hindered the formation of the zinc ferrite crystal with the effect of ultrasonic waves. Therefore, the crystal had preferable dispersability and uniformity. In the presence of ultrasonic waves, the activated component dispersed uniformly on activated carbon and formed the monolayer coverage to enhance the desulfurization ability of the $\mathrm{ZnFe}_{2} \mathrm{O}_{4} / \mathrm{AC}$ composite. As shown in Table 1 , the $\mathrm{ZnFe}_{2} \mathrm{O}_{4}$ load ratio declined after prolonging the ultrasonic time to 90 and

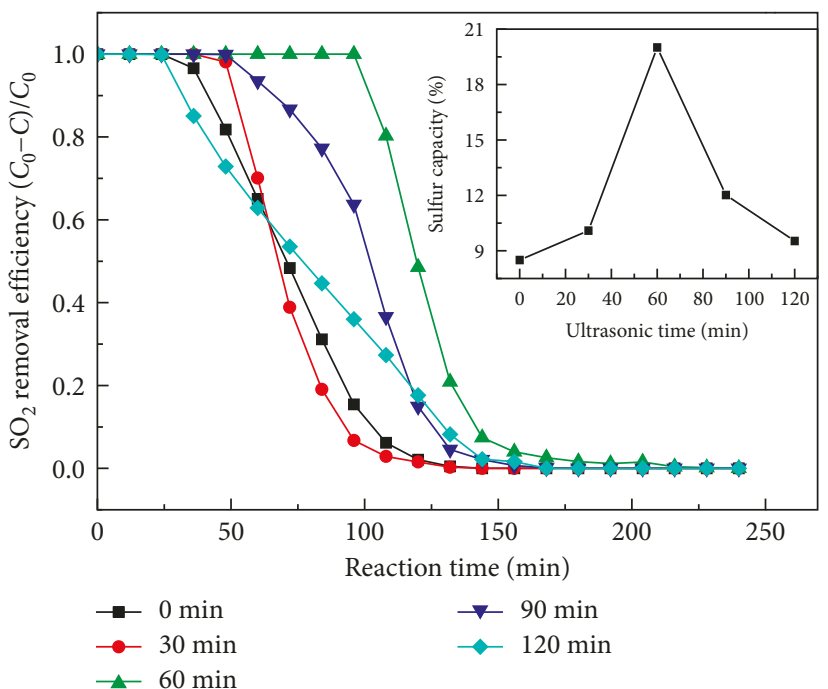

FIGURE 4: Effect of zinc ferrite/activated carbon at different ultrasonic time periods on desulfurization reactivity.

120 min. Combined with Figure 4, it can be seen that the sulfur capacity of the desulfurizer declined because of the declination in the loading rate efficiency of zinc ferrite.

\subsubsection{Effect of Hydrothermal Temperature on Desulfurization} Ability of $\mathrm{ZnFe}_{2} \mathrm{O}_{4} / \mathrm{AC}$ Composite. With the condition of the mass ratio of zinc ferrite to activated carbon being at $5: 5$ and the ultrasonic time at $60 \mathrm{~min}$, the impact of hydrothermal temperature on desulfurization ability of the $\mathrm{ZnFe}_{2} \mathrm{O}_{4} / \mathrm{AC}$ composite was discussed (Figure 5).

As shown in Figure 5, the desulfurization ability of the $\mathrm{ZnFe}_{2} \mathrm{O}_{4} / \mathrm{AC}$ composite first increased and then decreased with the increase of hydrothermal temperature. The optimal adsorption capacity of sulfur dioxide reached $20.01 \%$ at the hydrothermal temperature of $130^{\circ} \mathrm{C}$.

The hydrothermal temperature controlling was essential for the desulfurizer composite to form the desulfurization ability, and it influenced the allocation and growth of the crystal grain. During the hydrothermal reaction process, water was the solvent, and in the sealed pressure vessel, the chemical reaction was proceeded under the condition of high temperature and high pressure. The hydrothermal synthesis reaction was in the molecular level, enhancing the reactivity. The compound with the desulfurization ability generated in the preparation of the desulfurizer composite through a series of reactions. The different hydrothermal temperatures made a big difference in the desulfurization ability of the desulfurizer. Increasing the hydrothermal temperature not only can improve the growth of the zinc ferrite crystal grain but also can decline the efficient specific surface area and enhance the aperture of the desulfurizer.

\subsection{Characterization of $\mathrm{ZnFe}_{2} \mathrm{O}_{4} / \mathrm{AC}$ Composite}

3.2.1. SEM and EDS Studies. Figure 6 shows the SEM images of $\mathrm{AC}(\mathrm{a}), \mathrm{ZnFe}_{2} \mathrm{O}_{4}$ (b), $\mathrm{ZnFe}_{2} \mathrm{O}_{4} / \mathrm{AC}$ composite material at low magnification (c), and $\mathrm{ZnFe}_{2} \mathrm{O}_{4} / \mathrm{AC}$ composite material at high 
TABLE 1: Influence of ultrasonic time on the $\mathrm{ZnFe}_{2} \mathrm{O}_{4}$ load ratio.

\begin{tabular}{lccc}
\hline Ultrasonic time $(\mathrm{min})$ & The mass of the remaining $\mathrm{ZnFe}_{2} \mathrm{O}_{4}(\mathrm{~g})$ & The quality of the burned $\mathrm{AC}(\mathrm{g})$ & $\mathrm{The} \mathrm{ZnFe}_{2} \mathrm{O}_{4}$ load ratio $(\mathrm{g})$ \\
\hline 0 & 0.4139 & 0.5665 & 0.7306 \\
30 & 0.4119 & 0.5623 & 0.7325 \\
60 & 0.4210 & 0.5631 & 0.7476 \\
90 & 0.3929 & 0.5723 & 0.6865 \\
120 & 0.3534 & 0.5639 & 0.6267 \\
\hline
\end{tabular}

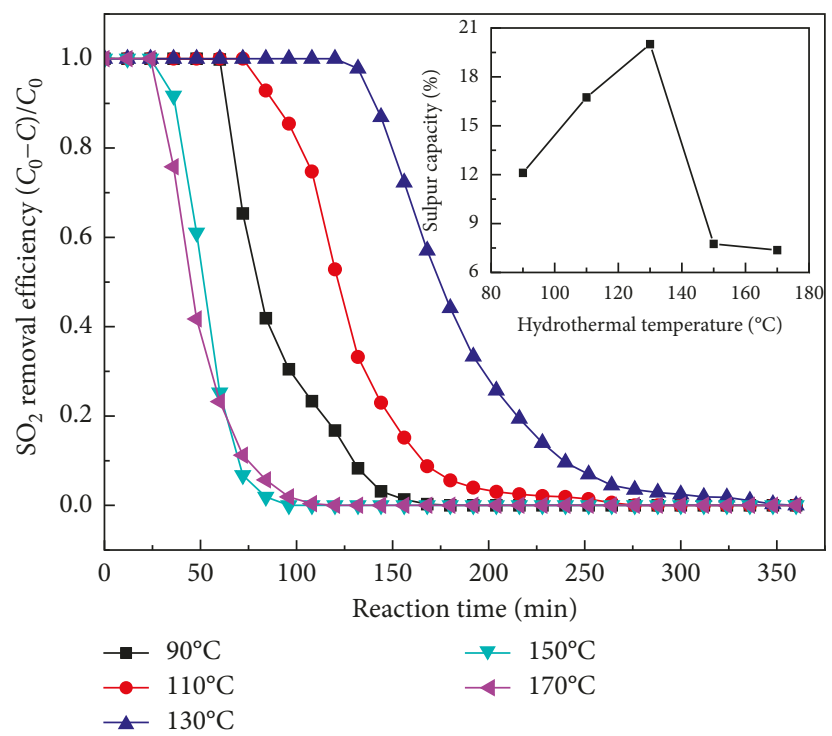

Figure 5: Effect of zinc ferrite/activated carbon at different hydrothermal reaction temperatures on desulfurization reactivity.

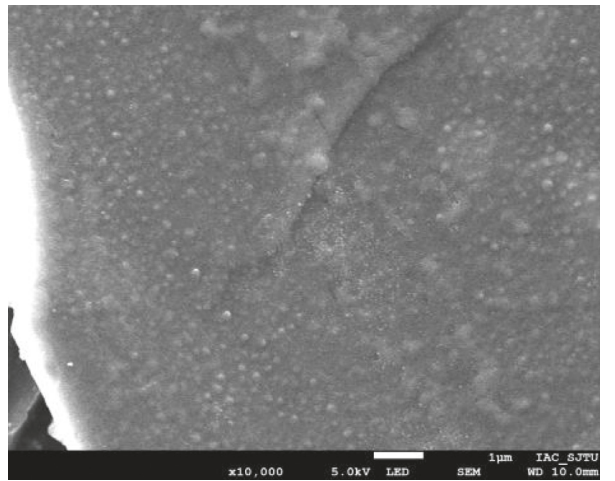

(a)

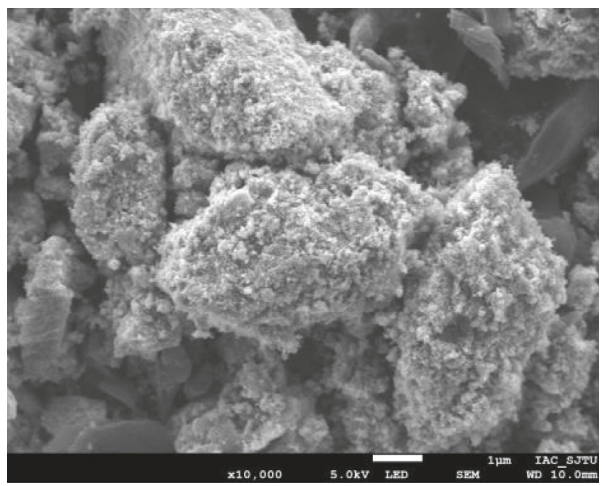

(c)

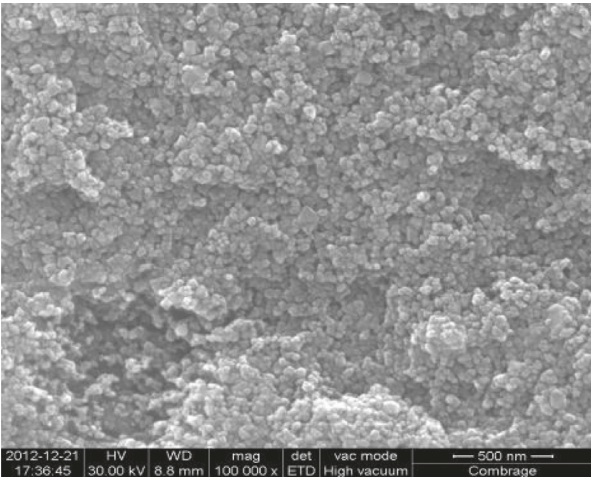

(b)

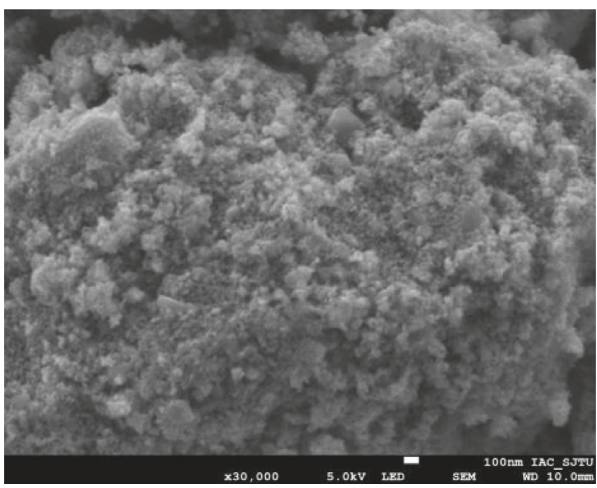

(d)

Figure 6: SEM images of (a) AC, (b) $\mathrm{ZnFe}_{2} \mathrm{O}_{4}$, (c) $\mathrm{ZnFe}_{2} \mathrm{O}_{4} / \mathrm{AC}$ at low magnification, and (d) $\mathrm{ZnFe}_{2} \mathrm{O}_{4} / \mathrm{AC}$ at high magnification. 


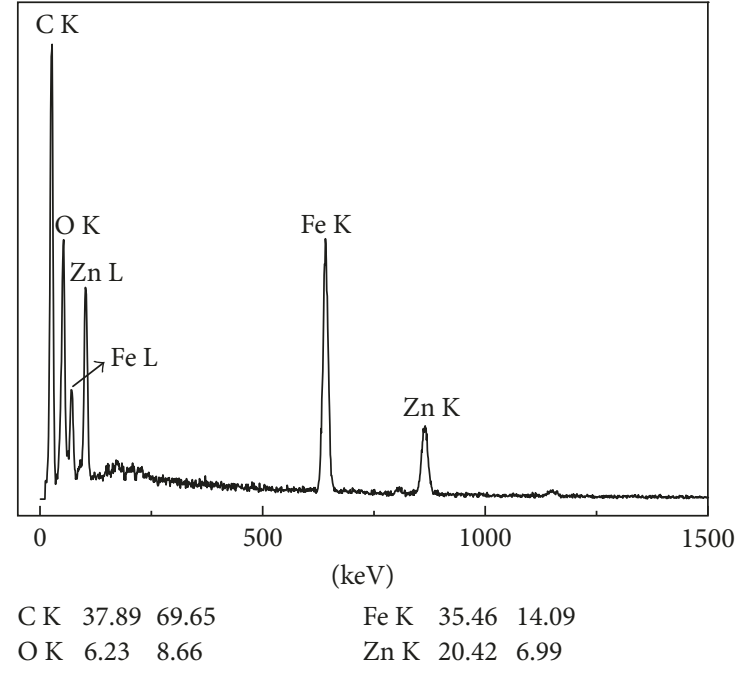

(a)

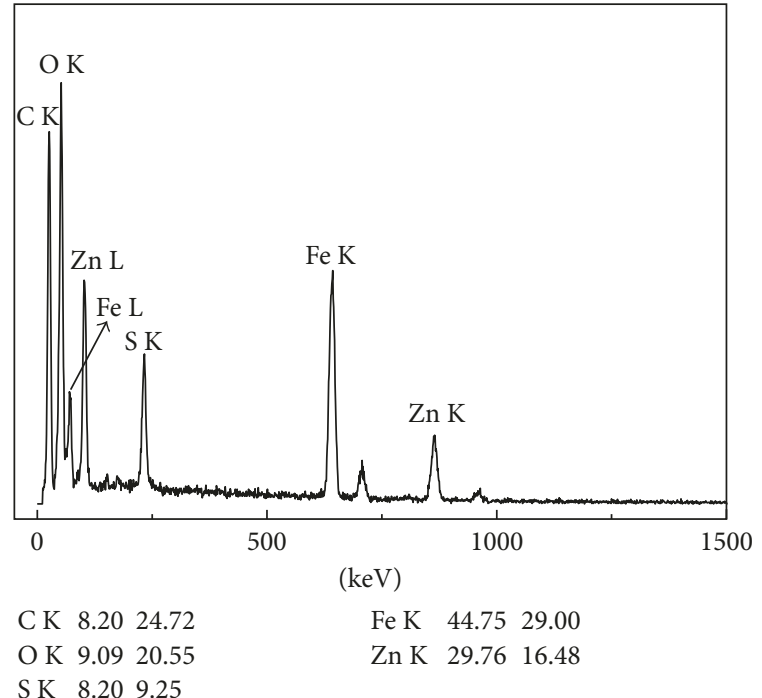

(b)

Figure 7: EDS pattern spectra of the SEM image of $\mathrm{ZnFe}_{2} \mathrm{O}_{4} / \mathrm{AC}$ : (a) fresh and (b) after experiment.

magnification (d). For $\mathrm{ZnFe}_{2} \mathrm{O}_{4} / \mathrm{AC}$ composite material, the diameter range was $20-50 \mathrm{~nm}$, which implied that it was uniform distributed diameter sphere. This kind of rough structure was beneficial to improve the adsorption performance and also to the transmission of $\mathrm{SO}_{2}$ gas on the adsorbent surface $[13,17]$.

The EDS analysis of the fresh $\mathrm{ZnFe}_{2} \mathrm{O}_{4} / \mathrm{AC}$ composite material sample and sulfated sample is shown in Figure 7. The spectrum clearly indicates the presence of $\mathrm{C}, \mathrm{Zn}, \mathrm{Fe}$, and $\mathrm{O}$ elements in $\mathrm{ZnFe}_{2} \mathrm{O}_{4} / \mathrm{AC}$ composite material powder. The determined atomic ratio of $\mathrm{Zn}$ to $\mathrm{Fe}$ in the powder was $1: 2.02$, which was in close proximity to the theoretical ratio in $\mathrm{ZnFe}_{2} \mathrm{O}_{4}$. As shown in Figure 7(b), S element appeared in the EDS spectrum of the sulfated sample; thus, it proved that the $\mathrm{SO}_{2}$ was adsorbed on the surface composite materials.

3.2.2. FT-IR and XRD Studies. The FT-IR spectra of the activated carbon sample and $\mathrm{ZnFe}_{2} \mathrm{O}_{4} / \mathrm{AC}$ composite in the range 4000-400 $\mathrm{cm}^{-1}$ are shown in Figure 8. Compared with $\mathrm{ZnFe}_{2} \mathrm{O}_{4}$ (a) and activated carbon (b), the FT-IR spectra of $\mathrm{ZnFe}_{2} \mathrm{O}_{4} / \mathrm{AC}$ composites (c) retain the original basic characteristic absorption peak. The spectrum clearly shows a broad absorption around $3400 \mathrm{~cm}^{-1}$, which was a characteristic stretching vibration of hydroxylate $(\mathrm{O}-\mathrm{H})$. Peaks localized at $2920 \mathrm{~cm}^{-1}$ and $2849 \mathrm{~cm}^{-1}$ are assigned to asymmetrical and symmetrical vibration of methylene $\left(-\mathrm{CH}_{2}-\right)$, respectively. Apart from the original characteristics of the activated carbon absorption peak at $\mathrm{ZnFe}_{2} \mathrm{O}_{4} / \mathrm{AC}$ (c), there are two obvious characteristic peaks in the range of 600-400 $\mathrm{nm}$ as same as the peak at $\mathrm{ZnFe}_{2} \mathrm{O}_{4}$ (a), corresponding to the wave numbers $559 \mathrm{~cm}^{-1}$ and $425 \mathrm{~cm}^{-1}$, which are considered to the infrared spectrum of ferrite composite compounds. The broad and intense band at $559 \mathrm{~cm}^{-1}$ was ascribed to the stretching of $\mathrm{Zn}-\mathrm{O}$ bond in tetrahedral cations. The broad and intense band at $425 \mathrm{~cm}^{-1}$

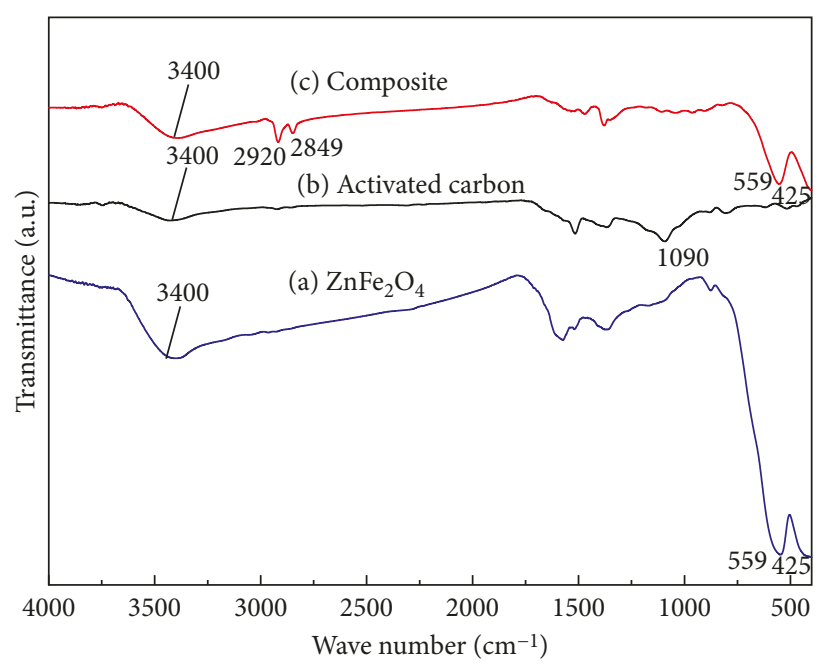

FIgURE 8: FT-IR spectra of activated carbon and $\mathrm{ZnFe}_{2} \mathrm{O}_{4} / \mathrm{AC}$ composite.

was attributed to the stretching of $\mathrm{Fe}-\mathrm{O}$ bond in octahedral cations. In addition to these characteristic peaks, it can be seen that there was no other impurity peak in zinc ferrite.

$\mathrm{X}$-ray diffraction patterns for activated carbon, $\mathrm{ZnFe}_{2} \mathrm{O}_{4}$, and $\mathrm{ZnFe}_{2} \mathrm{O}_{4} / \mathrm{AC}$ system were presented in Figure 9. The activated carbon was presented an undefined structure, which has been pretreated. The zinc ferrite spinel has been loaded on the activated carbon when compared with $\mathrm{ZnFe}_{2} \mathrm{O}_{4}$ and $\mathrm{ZnFe}_{2} \mathrm{O}_{4} / \mathrm{AC}$. These diffraction lines provide clear evidence of the formation of single-phase cubic spine structure. All the diffraction peaks were indexed to the cubic structured literature (JCPDS card number 89-1012, with $\alpha=8.433 \AA$ ) [21].

3.2.3. BET Analyses. Figure 10 shows the $\mathrm{N}_{2}$ adsorption/ desorption isotherms of $\mathrm{AC}, \mathrm{ZnFe}_{2} \mathrm{O}_{4}$, and $\mathrm{ZnFe}_{2} \mathrm{O}_{4} / \mathrm{AC}$. Table 2 shows the specific surface area, pore volume, and 




Figure 9: XRD patterns of (a) activated carbon, (b) $\mathrm{ZnFe}_{2} \mathrm{O}_{4}$, and (c) $\mathrm{ZnFe}_{2} \mathrm{O}_{4} / \mathrm{AC}$ composite.

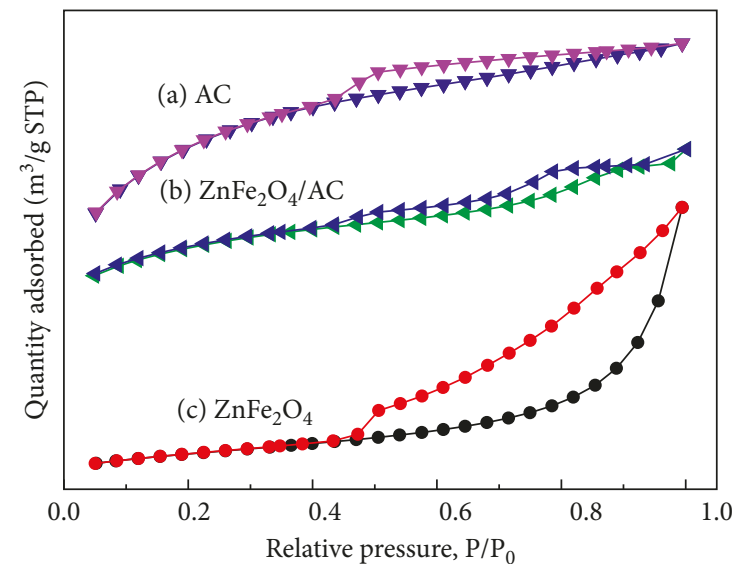

(a)

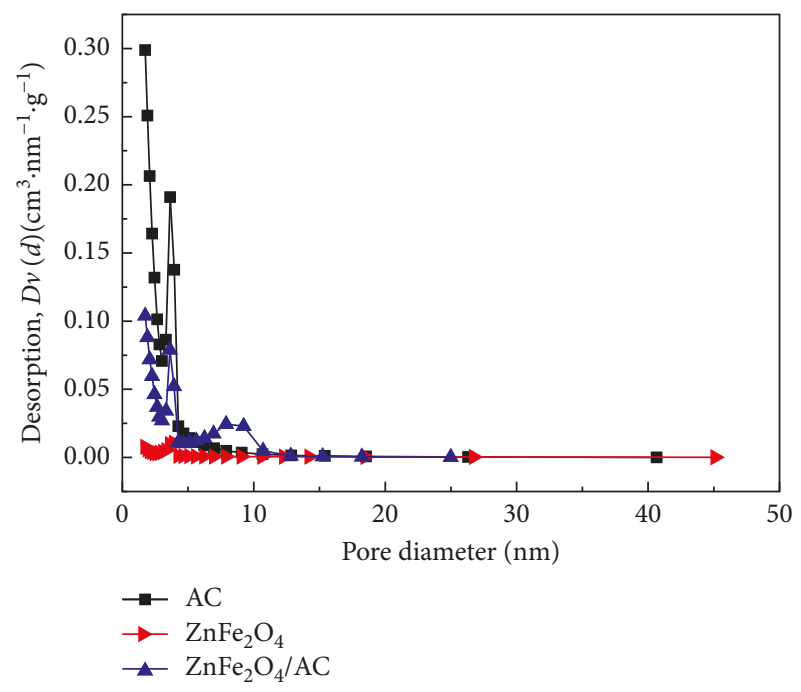

(b)

FIGURE 10: $\mathrm{N}_{2}$ adsorption-desorption isotherms and pore size distribution of $\mathrm{AC}, \mathrm{ZnFe}_{2} \mathrm{O}_{4}$, and $\mathrm{ZnFe}_{2} \mathrm{O}_{4} / \mathrm{AC}$ composite.

average pore diameter of the samples. The profiles reveal that the adsorption curves of $\mathrm{AC}$ and $\mathrm{ZnFe}_{2} \mathrm{O}_{4} / \mathrm{AC}$ are similar. The isotherm of modified activated carbon exhibits a high Type I adsorption/desorption shape with an $\mathrm{H} 4$ hysteresis loop in the IUPAC classification. $\mathrm{ZnFe}_{2} \mathrm{O}_{4}$ shows a Type IV isotherm and an $\mathrm{H} 3$ hysteresis loop. The $y$-axis of the three materials at the low-pressure end indicates that the material has stronger force with nitrogen. When the micropores are present, the adsorption curve was Type I or IV due to the strong adsorption potential, and the pressure end was mostly due to nitrogen condensate accumulation in the material channel, showing a steady trend. It's high-pressure side that is related with the degree of particle accumulation, which can explain the particles may not be uniform through the Type I in the rise of High-pressure side. It can be seen from the graph that the adsorption capacity increases slowly in the low-pressure stage. At this time, the $\mathrm{N}_{2}$ molecules adsorb on the inner surface of the mesopores in a single layer to multiple layers. $\mathrm{N}_{2}$ adsorption was the amount of physical adsorption, and the size of the specific surface area 
TABLE 2: Characteristics of activated carbon.

\begin{tabular}{|c|c|c|c|}
\hline \multirow{2}{*}{ Sample } & \multicolumn{3}{|c|}{ Pore structural parameters } \\
\hline & Specific surface area $\left(\mathrm{m}^{2} \cdot \mathrm{g}^{-1}\right)$ & Pore volume $\left(\mathrm{cm}^{3} \cdot \mathrm{g}^{-1}\right)$ & Average pore size $(\mathrm{nm})$ \\
\hline $\mathrm{AC}$ & 1273.62 & 0.797 & 2.487 \\
\hline $\mathrm{ZnFe}_{2} \mathrm{O}_{4} / \mathrm{AC}$ & 435.87 & 0.377 & 3.42 \\
\hline $\mathrm{ZnFe}_{2} \mathrm{O}_{4}$ & 146.37 & 0.507 & 13.69 \\
\hline
\end{tabular}

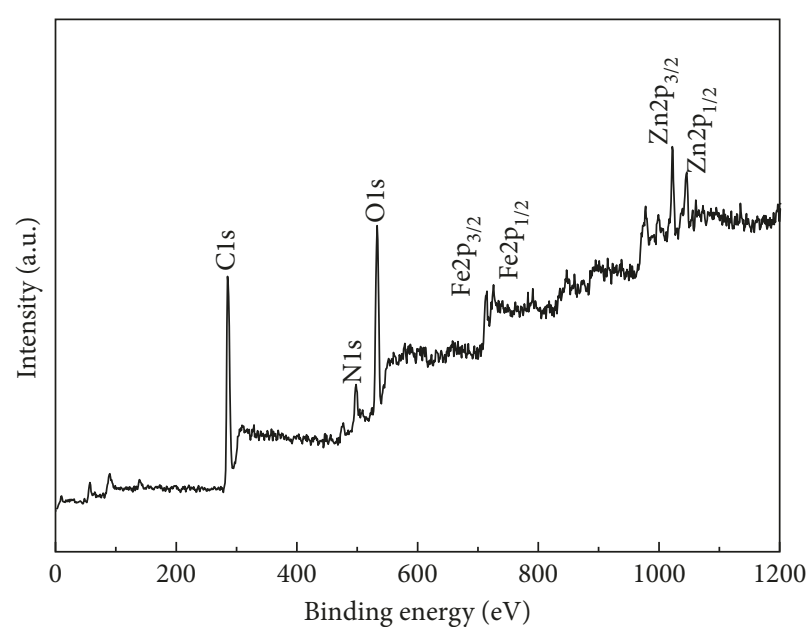

(a)

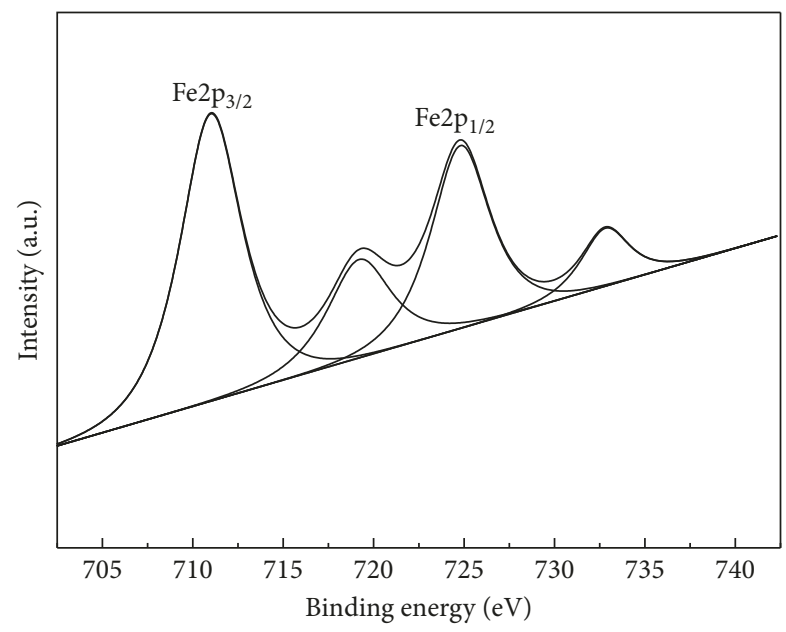

(c)

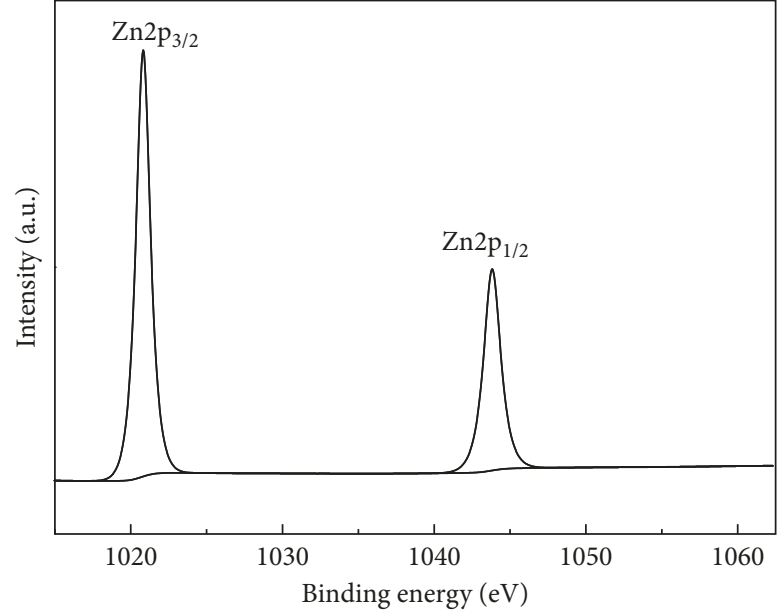

(b)

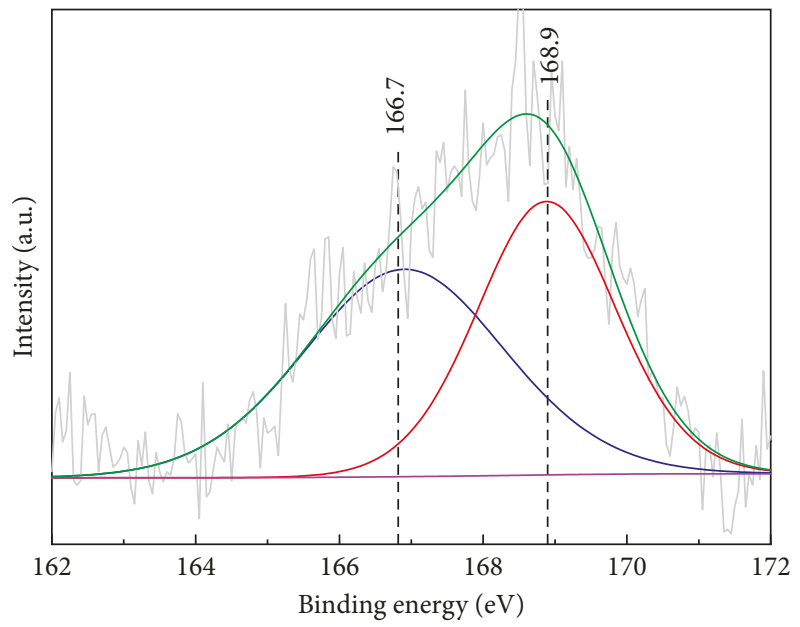

(d)

FIGURE 11: XPS spectrum of the $\mathrm{ZnFe}_{2} \mathrm{O}_{4} / \mathrm{AC}$ composite: (a) the score of the composite; (b) fitting of Zn2p peak; (c) fitting of Fe2p peak; (d) fitting of S2p peak.

corresponding to the modified activated carbon adsorption on the $\mathrm{N}_{2}$ decreased with the corresponding reduction in the surface area [7, 17]. Table 2 shows that AC has a specific surface area of $1273.6 \mathrm{~m}^{2} \cdot \mathrm{g}^{-1}$ and a pore size of $2.48 \mathrm{~nm}$. The specific surface area of $\mathrm{ZnFe}_{2} \mathrm{O}_{4} / \mathrm{AC}$ was reduced to $435.9 \mathrm{~m}^{2} \cdot \mathrm{g}^{-1}$. After the load modification, the adsorption curve appeared to change the position of the hysteresis loop. The position of $\mathrm{P} / \mathrm{P}_{0}$ was changed from $0.45 \sim 1.0$ to $0.30 \sim 1.0$, which belonged to the micropore adsorption before the hysteresis loop. Mesoporous adsorption after the hysteresis loop indicated that the pore size was increased after modification. Table 2 shows that the pore size increased by about
$1 \mathrm{~nm}$, which may be caused by the problem of the accumulation and density of samples during the composite modification process. The metal oxide blocks some of the pores, reduces pore volume, and increases the average pore size [11].

3.2.4. XPS Characterization. Figure 11 shows that the surface elemental composition and valence of $\mathrm{ZnFe}_{2} \mathrm{O}_{4} / \mathrm{AC}$ were characterized by XPS. The binding energy of $\mathrm{C} 1 \mathrm{~s}$ was $284.5 \mathrm{eV}$, which was assigned to graphite carbon. Figure 11(a) shows that the prepared samples contain peaks of $\mathrm{Zn}, \mathrm{Fe}, \mathrm{O}$, C, and N. Figure 11(b) shows that the binding energies at 




Figure 12: Comparison of the sulfur capacity of $\mathrm{AC}, \mathrm{ZnFe}_{2} \mathrm{O}_{4}$, and $\mathrm{ZnFe}_{2} \mathrm{O}_{4} / \mathrm{AC}$ composites.

$1021.4 \mathrm{eV}$ and $1044.4 \mathrm{eV}$, respectively, correspond to $\mathrm{Zn} 2 \mathrm{p}_{3 / 2}$ and $\mathrm{Zn} 2 \mathrm{p}_{1 / 2}$, which means that the main valence of zinc was +2 on the surface of the sample. Figure 11(c) shows that the Fe element contains two more obvious peaks at $710.9 \mathrm{eV}$ and $724.4 \mathrm{eV}$ corresponding to $\mathrm{Fe}^{2+}$ and $\mathrm{Fe}^{3+}$ corresponding to the peaks of $\mathrm{Fe} 2 \mathrm{p}_{3 / 2}$ and $\mathrm{Fe} 2 \mathrm{p}_{1 / 2}$. The oxidation state of iron coexists with the mixed phase because there was a weak peak at the binding energy of $719.1 \mathrm{eV}$, which coincides with the reported $\mathrm{Fe}^{3+}$ compound. The proportion of the two elements can be seen, and the material is $\mathrm{ZnFe}_{2} \mathrm{O}_{4}$.

The S2p peak appeared in the XPS high-resolution energy spectrum after the treatment of $\mathrm{ZnFe}_{2} \mathrm{O}_{4} / \mathrm{AC}$ with $\mathrm{SO}_{2}$. To analyze these spectra in more detail and to apply literature data for comparison, we deconvoluted the S2p lines into two components. The comparison with literature data allows unambiguous assignment of these $\mathrm{S} 2 \mathrm{p}_{3 / 2}$ features to sulfite (165.8-167.5) and sulfate (168.9-171.1) species [2]. Figure 11(d) shows that the binding energies of the peak of sulfur were $166.7 \mathrm{eV}$ and $168.9 \mathrm{eV}$, which are in good agreement with $\mathrm{SO}_{3}^{2-}$ and $\mathrm{SO}_{4}^{2-}$ states, respectively. Therefore, the $\mathrm{ZnFe}_{2} \mathrm{O}_{4} / \mathrm{AC}$ composite surface contains a certain amount of both sulfite and sulfate species after the adsorption of $\mathrm{SO}_{2}$, which further indicates that the chemical adsorption took place [23].

3.3. Adsorption of $\mathrm{SO}_{2}$. Figure 12 shows the $\mathrm{SO}_{2}$ adsorption abilities of $\mathrm{AC}, \mathrm{ZnFe}_{2} \mathrm{O}_{4}$ particles, and the $\mathrm{ZnFe}_{2} \mathrm{O}_{4} / \mathrm{AC}$ sample at the self-made desulfurization equipment. It was seen that the adsorption capacity of the $\mathrm{ZnFe}_{2} \mathrm{O}_{4} / \mathrm{AC}$ composite is much higher than that of the $\mathrm{AC}$ and $\mathrm{ZnFe}_{2} \mathrm{O}_{4}$ samples. This suggests that the $\mathrm{ZnFe}_{2} \mathrm{O}_{4} / \mathrm{AC}$ composite should be a better adsorbent for $\mathrm{SO}_{2}$ abatement. The pure $\mathrm{ZnFe}_{2} \mathrm{O}_{4}$ was mainly in the form of powder, which was easy to agglomerate and adversely affected its desulfurization performance [22]. The presence of activated carbon as a carrier can improve the dispersing property of $\mathrm{ZnFe}_{2} \mathrm{O}_{4}$, reduce the size of $\mathrm{ZnFe}_{2} \mathrm{O}_{4}$ aggregates, and improve the desulfurization activity of $\mathrm{ZnFe}_{2} \mathrm{O}_{4}$. The adsorption capacity was consistent with the surface area, pore size distribution, and active principal part of the adsorbent. A substantial percentage of pores for the $\mathrm{ZnFe}_{2} \mathrm{O}_{4} / \mathrm{AC}$ composite was now in the quasi-micropore region (below $5 \mathrm{~nm}$ ), and molecules may be adsorbed following the micropore-filling mechanism before they enter the pore body. Because the pore opening was smaller than the pore body, molecules will have difficulty in escaping once they have been adsorbed into the pore body. But the $\mathrm{SO}_{2}$ removal capacity of the $\mathrm{AC}$ was only $5.32 \%$, which indicated that the physical adsorption of AC on the $\mathrm{SO}_{2}$ was smaller. The $\mathrm{SO}_{2}$ removal effect of the composite was mainly composed of activated carbon and surface-supported $\mathrm{ZnFe}_{2} \mathrm{O}_{4}$.

\section{Conclusion}

In this paper, $\mathrm{ZnFe}_{2} \mathrm{O}_{4} / \mathrm{AC}$ was successfully prepared by hydrothermal synthesis using activated carbon as the carrier. The best preparation conditions were as follows: the ratio of $\mathrm{ZnFe}_{2} \mathrm{O}_{4}$ to $\mathrm{AC}$ was $1: 1$, ultrasonic time was $60 \mathrm{~min}$, and the hydrothermal reaction temperature was maintained at $130^{\circ} \mathrm{C} . \mathrm{ZnFe}_{2} \mathrm{O}_{4} / \mathrm{AC}$ was characterized by SEM, FT-IR, XRD, EDS, BET, and XPS. The results concluded that $\mathrm{ZnFe}_{2} \mathrm{O}_{4} / \mathrm{AC}$ has a rough structure, much higher surface area, and pore volume. The structure of $\mathrm{ZnFe}_{2} \mathrm{O}_{4} / \mathrm{AC}$ should be a better adsorbent for $\mathrm{SO}_{2}$ abatement. The results from XPS reveal that sulfite and sulfate species can be formed on the surface of $\mathrm{ZnFe}_{2} \mathrm{O}_{4} / \mathrm{AC}$. Compared with $\mathrm{ZnFe}_{2} \mathrm{O}_{4}$ and $\mathrm{AC}$, the desulfurization performance of $\mathrm{ZnFe}_{2} \mathrm{O}_{4} / \mathrm{AC}$ has been greatly improved showing the synergistic effect. The product of the breakdown time was $147 \mathrm{~min}$, and the sulfur capacity was $20.01 \%$ in the desulfurization performance test.

\section{Conflicts of Interest}

The authors declare that they have no conflicts of interest.

\section{Acknowledgments}

The authors gratefully acknowledge the Science and Technology Project of Cooperation in Universities and Colleges in Fujian Province (no. 2014H6013) and Technical Innovation Items of Enterprises in Fujian Province for the financial support.

\section{References}

[1] H. Yi, Y. Zuo, H. Liu et al., "Simultaneous removal of $\mathrm{SO}_{2}$, $\mathrm{NO}$, and $\mathrm{CO}_{2}$ on metal-modified coconut shell activated carbon," Water, Air, \& Soil Pollution, vol. 225, no. 5, pp. 1965-1972, 2014.

[2] K. Gotterbarm, F. Späth, U. Bauer, H.-P. Steinrück, and C. Papp, "Adsorption and reaction of $\mathrm{SO}_{2}$ on graphenesupported Pt nanoclusters," Topics in Catalysis, vol. 58, no. 10-11, pp. 573-579, 2015.

[3] C. Yao, Z. Jiayong, and W. Zuwu, "Plasma modification of activated carbon fibers for adsorption of $\mathrm{SO}_{2}$," Plasma Science and Technology, vol. 15, no. 10, pp. 1047-1052, 2013.

[4] S. Sumathi, S. Bhatia, K. T. Lee, and A. R. Mohamed, "Adsorption isotherm models and properties of $\mathrm{SO}_{2}$, and $\mathrm{NO}$ 
removal by palm shell activated carbon supported with cerium (Ce/PSAC)," Chemical Engineering Journal, vol. 162, no. 1, pp. 194-200, 2010.

[5] X. Liu, F. Sun, Z. Qu, J. Gao, and S. Wu, "The effect of functional groups on the $\mathrm{SO}_{2}$, adsorption on carbon surface I: a new insight into noncovalent interaction between $\mathrm{SO}_{2}$, molecule and acidic oxygen-containing groups," Applied Surface Science, vol. 369, pp. 552-557, 2016.

[6] M. T. Izquierdo and B. Rubio, "Carbon-enriched coal fly ash as a precursor of activated carbons for $\mathrm{SO}_{2}$ removal," Journal of Hazardous Materials, vol. 155, no. 1-2, pp. 199-205, 2008.

[7] L. Shi, K. Yang, Q. Zhao, H. Wang, and Q. Cui, "Characterization and mechanisms of $\mathrm{H}_{2} \mathrm{~S}$ and $\mathrm{SO}_{2}$ adsorption by activated carbon," Energy \& Fuels, vol. 29, no. 10, pp. 66786685, 2015.

[8] L. I. Fenrong, Y. I. Honghong, X. Tang, P. Ning, Q. Yu, and D. Kang, "Adsorption of carbon dioxide by coconut activated carbon modified with Cu/Ce," Journal of Rare Earths, vol. 28, no. 1, pp. 334-337, 2010.

[9] H. H. Tseng, M. Y. Wey, Y. S. Liang, and K.-H. Chen, "Catalytic removal of $\mathrm{SO}_{2}, \mathrm{NO}$ and $\mathrm{HCl}$ from incineration flue gas over activated carbon-supported metal oxides," Carbon, vol. 41, no. 5, pp. 1079-1085, 2003.

[10] H. H. Tseng and M. Y. Wey, "Study of $\mathrm{SO}_{2}$, adsorption and thermal regeneration over activated carbon-supported copper oxide catalysts," Carbon, vol. 42, no. 11, pp. 2269-2278, 2004.

[11] B. Rubio and M. T. Izquierdo, "Coal fly ash based carbons for $\mathrm{SO}_{2}$ removal from flue gases," Waste Management, vol. 30, no. 7, pp. 1341-1347, 2010.

[12] S. I. Ji, S. J. Park, T. Kim, and Y.-S. Lee, "Hydrogen storage evaluation based on investigations of the catalytic properties of metal/metal oxides in electrospun carbon fibers," International Journal of Hydrogen Energy, vol. 34, no. 8, pp. 3382-3388, 2009.

[13] X. C. Liu, Y. Osaka, H. Y. Huang et al., "Development of lowtemperature desulfurization performance of a $\mathrm{MnO}_{2} / \mathrm{AC}$ composite for a combined $\mathrm{SO}_{2}$ trap for diesel exhaust," RSC Advances, vol. 6, no. 98, pp. 96367-96375, 2016.

[14] C. Tekmen, Y. Tsunekawa, and H. Nakanishi, "Electrospinning of carbon nanofiber supported $\mathrm{Fe} / \mathrm{Co} / \mathrm{Ni}$ ternary alloy nanoparticles," Journal of Materials Processing Technology, vol. 210, no. 3, pp. 451-455, 2010

[15] S. K. Nataraj, B. H. Kim, J. H. Yun, D. H. Lee, T. M. Aminabhavi, and K. S. Yang, "Effect of added nickel nitrate on the physical, thermal and morphological characteristics of polyacrylonitrile-based carbon nanofibers," $M a$ terials Science \& Engineering B, vol. 162, no. 2, pp. 75-81, 2009.

[16] J. Li, N. Kobayashi, and Y. Hu, "Performance of $\mathrm{V}_{2} \mathrm{O}_{5} / \mathrm{AC}$ activated with the flue gas on $\mathrm{SO}_{2}$ removal," Journal of Environment \& Engineering, vol. 4, no. 1, pp. 176-187, 2009.

[17] S. Hosseini, I. Bayesti, E. Marahel et al., "Adsorption of carbon dioxide using activated carbon impregnated with $\mathrm{Cu}$ promoted by zinc," Journal of the Taiwan Institute of Chemical Engineers, vol. 52, no. 2, pp. 109-117, 2015.

[18] J. Ding, Q. Zhong, and S. Zhang, "ChemInform abstract: simultaneous removal of $\mathrm{NO}_{\mathrm{x}}$ and $\mathrm{SO}_{2}$ with $\mathrm{H}_{2} \mathrm{O}_{2}$ over $\mathrm{Fe}$ based catalysts at low temperature," Cheminform, vol. 45, no. 26, pp. 5394-5398, 2013.

[19] S. J. Lee, S. Y. Jung, S. C. Lee et al., " $\mathrm{SO}_{2}$ removal and regeneration of $\mathrm{MgO}$-based sorbents promoted with titanium oxide," Industrial \& Engineering Chemistry Research, vol. 48, no. 5, pp. 2691-2696, 2011.

[20] J. Podwórny, J. Piotrowski, and J. Wojsa, "Investigations into the kinetics and mechanism of gas-solid state processes in
MgO-MgRO (R: Al, Cr, Fe) spinels $\mathrm{SO}_{2}$ system," Ceramics International, vol. 34, no. 7, pp. 1587-1593, 2008.

[21] M. Su, C. He, V. K. Sharma et al., "Mesoporous zinc ferrite: synthesis, characterization, and photocatalytic activity with $\mathrm{H}_{2} \mathrm{O}_{2}$ /visible light," Journal of Hazardous Materials, vol. 211212, no. 2, pp. 95-103, 2012.

[22] F. Sun, J. Gao, Y. Zhu, G. Chen, S. Wu, and Y. Qin, "Adsorption of $\mathrm{SO}_{2}$ by typical carbonaceous material: a comparative study of carbon nanotubes and activated carbons," Adsorption, vol. 19, no. 5, pp. 959-966, 2013.

[23] Z. Tan, J. Qiu, J. Xiang et al., "Adsorptive removal of $\mathrm{SO}_{2}$, from coal burning by bamboo charcoal," in Cleaner Combustion and Sustainable World, vol. 10, no. 2, pp. 441-446, Berlin, Heidelberg, 2013. 


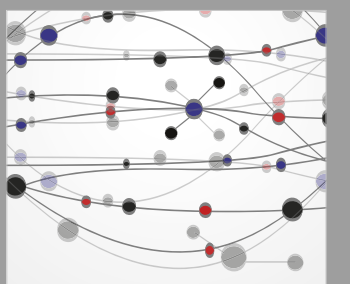

The Scientific World Journal
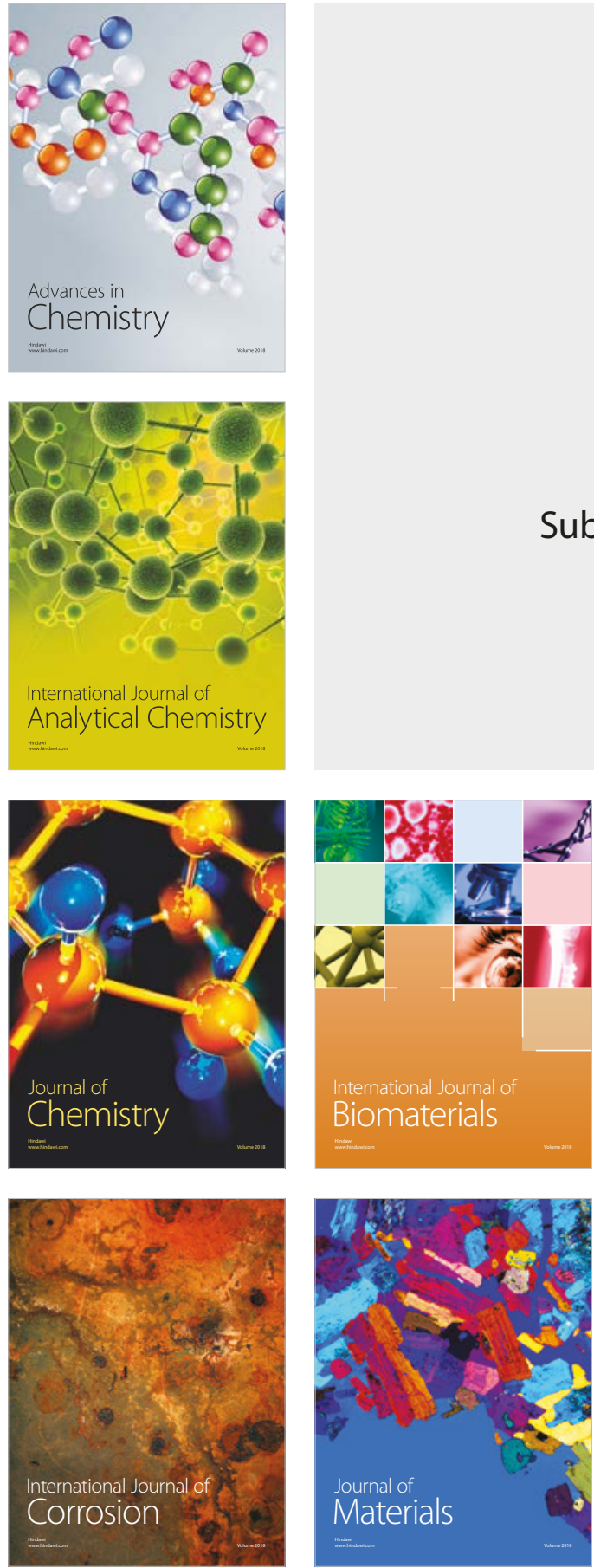

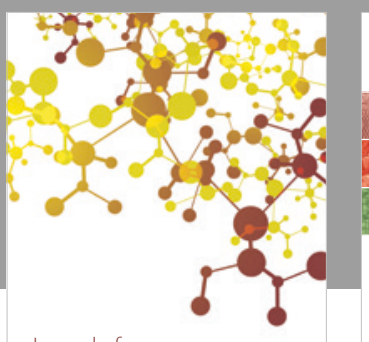

Journal of

Applied Chemistry
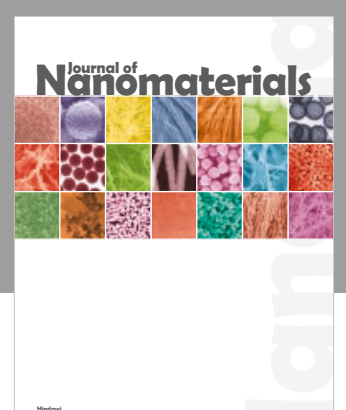

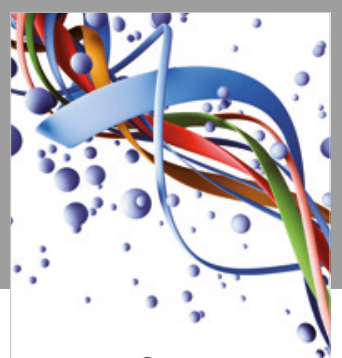

Scientifica

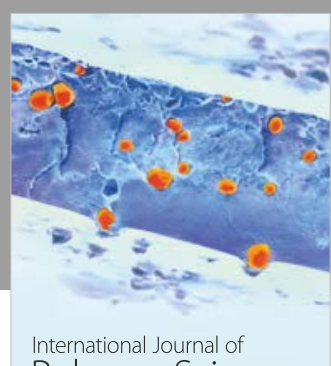

Polymer Science

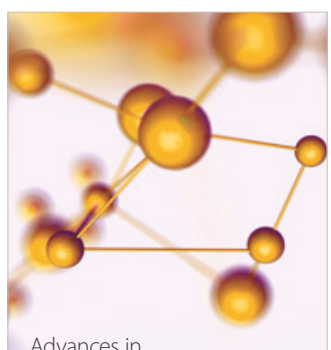

Physical Chemistry
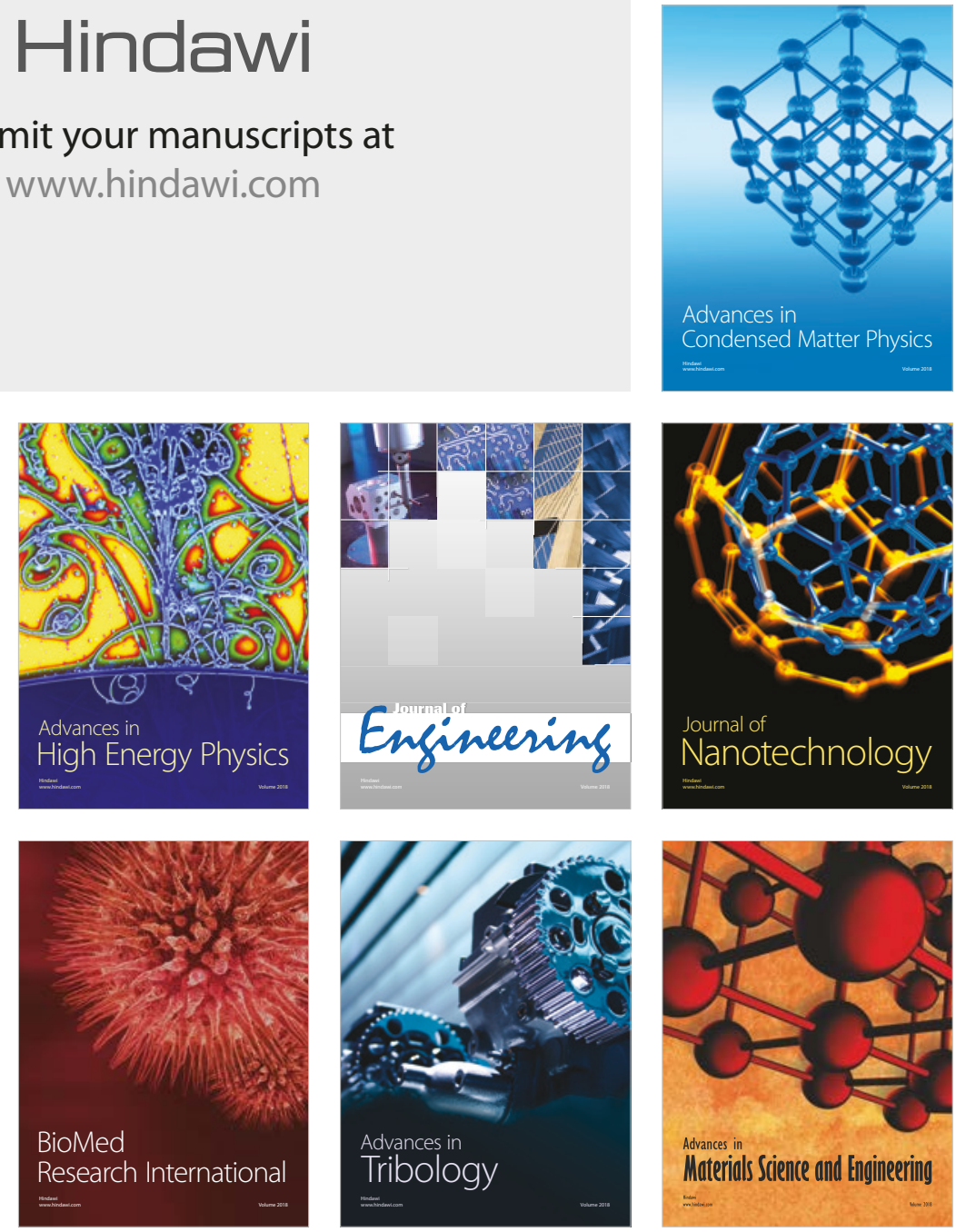